\title{
Effects of Immunosuppressant Agents on Growth Hormone Release and Gene Expression
}

\author{
Hidemi OHYE, MAKoto SATO, SHuji MATSUBARA, ToMoyo OHYAMA, \\ KOJI MURAO, AND JIRO TAKAHARA
}

First Department of Internal Medicine, Kagawa Medical University, Kagawa 761-07, Japan

THE immunosuppressant drug, FK506 (FK), acts through its binding protein, FK-binding protein (FKBP12) to suppress the function of T lymphocytes with relative selectivity [1-3]. Recent reports have indicated that FKBPs are widely distributed in the central nervous system [4] including the hypothalamus, suggesting biological effects of FK on brain and neuroendocrine functions. Antoni $e t$ al. reported that FK stimulates ACTH secretion from AtT20 mouse pituitary corticotrope tumor cells [5]. We have also reported that FK stimulates both GH secretion and gene expression of hypothalamic $\mathrm{GH}$ releasing hormone (GRH) in rats [6]. Although dual actions of FK to the hypothalamus and pituitary have been indicated in this paper, the intracellular signaling pathway has not yet been elucidated.

Other principal immunosuppressant drugs, cyclosporin $\mathrm{A}(\mathrm{CyA})$ and rapamycin (RP) bind to cyclophillin and FKBP12, respectively [2]. The major target of CyA-cyclosphillin complex is a calcium and calmodulin dependent protein phosphatase, calcineurin (CaN), similar to FK, but $\mathrm{RP}$ does not affect $\mathrm{CaN}$ activity [2,7], so that the signaling processes of these drugs are different. To investigate the intracellular signaling pathway in FK-induced GH release, these drugs were used in combination with FK in the present study. We also investigated whether FK stimulates not only

Correspondence to: Dr. Makoto SATO, First Department of Internal Medicine, Kagawa Medical University, 1750-1 Ikenobe, Miki-cho, Kita-gun, Kagawa 761-07, Japan Key words: GH, Immunosuppressant, FK506, Cyclosporin, Rapamycin
GH release, but also GH gene expression, because it is well established that the effects of FK are chiefly due to genomic action on target genes such as interleukin 2 in the T lymphocytes.

\section{Materials and Methods}

Primary culture of rat anterior pituitary cells was prepared as previously described [8]. Cultured pituitary cells were treated with $\mathrm{CyA}, \mathrm{RP}$ and tumor growth factor- $\beta$ (TGF- $\beta$ ) in the presence or absence of $\mathrm{FK}$, and $\mathrm{GH}$ release in the culture medium was examined with a rat GH RIA kit supplied by NIDDK. Primary transcripts of rat GH gene were examined by the intron-specific polymerase chain reaction (PCR) method as follows. PCR primers were designed to amplify a $234 \mathrm{bp}$ fragment from intron $C$ to intron $D$ of the rat $G H$ gene [9]. The sense primer was $5^{\prime}$-TCACTAGCTAATGCACAGC$3^{\prime}$ and the antisense primer was 5'-GTATAACCTCAGGCTAGCG-3'. Sequence analysis of the PCR product with this pair of primers confirmed the rat GH gene. Total RNA was extracted from cultured rat anterior pituitary cells and then treated with DNase I to remove the residual contamination of genomic DNA. RNA was reverse transcribed into CDNA and PCR was performed as previously described [10]. PCR products were electrophoresed in agarose gel containing ethidium bromide and photographed. Statistical comparisons were made by one-way analysis of variance and Student's $t$ test, with $P<0.05$ being considered significant. 


\section{Results}

Two-hour incubation with FK significantly increased $\mathrm{GH}$ release from cultured rat anterior pituitary cells in a dose-dependent manner (Fig. 1). The maximal effect was found at a concentration of $10 \mu \mathrm{M}$. RP had no effect on $\mathrm{GH}$ release, whereas CyA moderately, but significantly, augmented GH release (Fig. 2). FK-induced $\mathrm{GH}$ release was

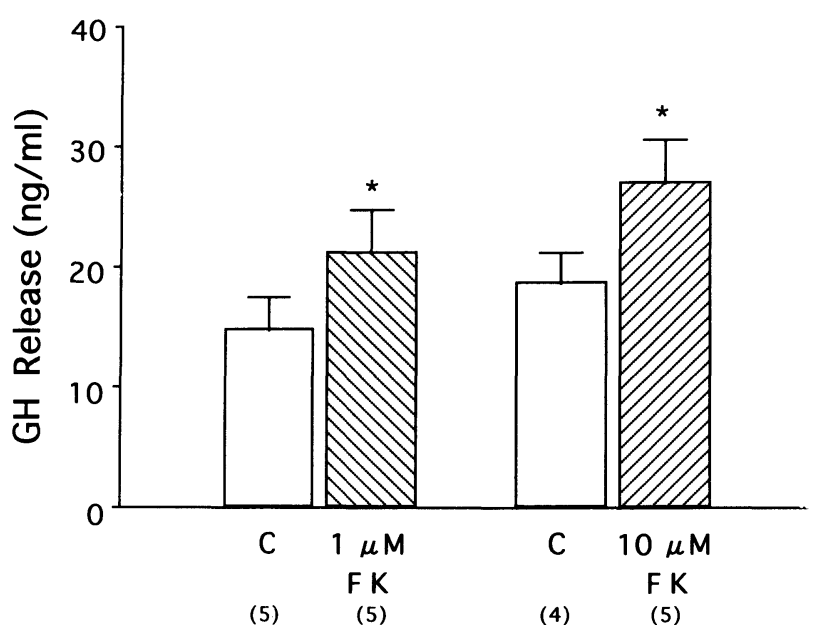

Fig. 1. Effects of FK on GH release from cultured rat anterior pituitary cells. The cells were incubated with FK for $2 \mathrm{~h}$. Vertical lines represent the SEM. ${ }^{*} P<0.05$ vs. control (c). Numbers in parentheses indicate the number of observations in each group.

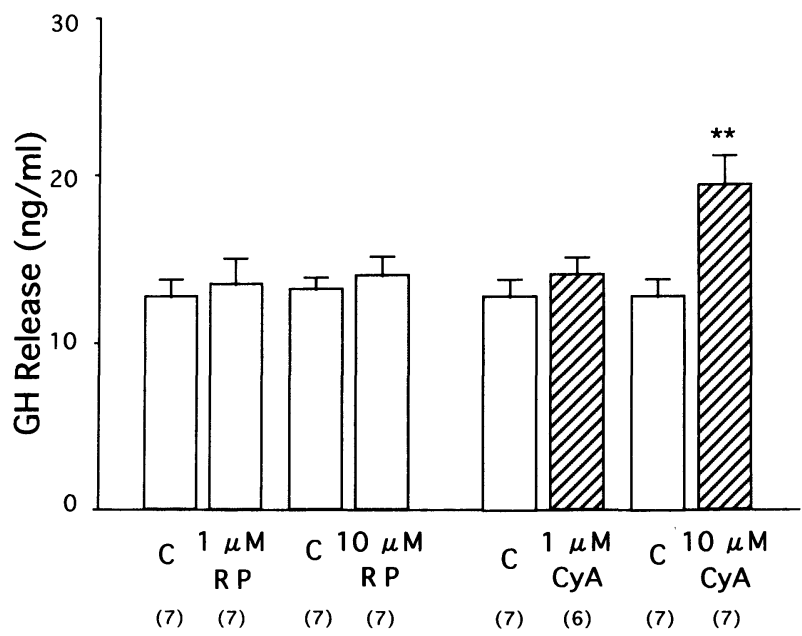

Fig. 2. Effects of RP and CyA on GH release from cultured rat anterior pituitary cells. The cells were incubated with RP or CyA for $2 \mathrm{~h}$. Vertical lines represent the SEM. ${ }^{* *} P<0.01$ vs. control (c). Numbers in parentheses indicate the number of observations in each group. significantly inhibited by coincubation with RP (Fig. 3 ). Tumor growth factor- $\beta$ (TGF- $\beta$ ) did not affect basal GH release, but FK-induced GH release was significantly inhibited by coincubation with TGF- $\beta$ (Fig. 4). Expression of the primary transcripts of

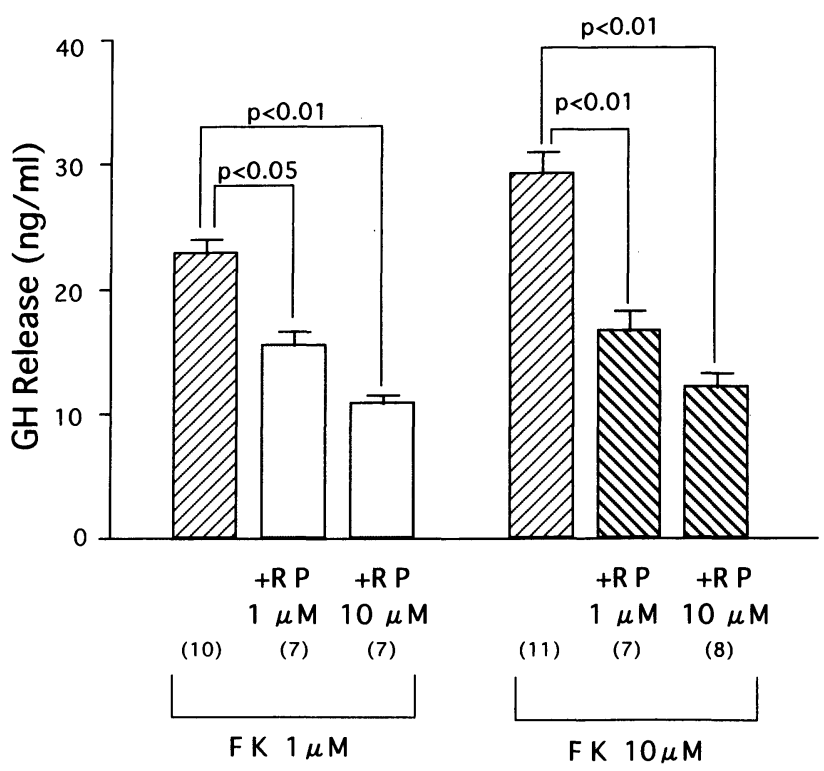

Fig. 3. Effects of RP on FK-induced GH release from cultured rat anterior pituitary cells. The cells were treated with RP in the presence of FK for $2 \mathrm{~h}$. Vertical lines represent the SEM. Numbers in parentheses indicate the number of observations in each group.

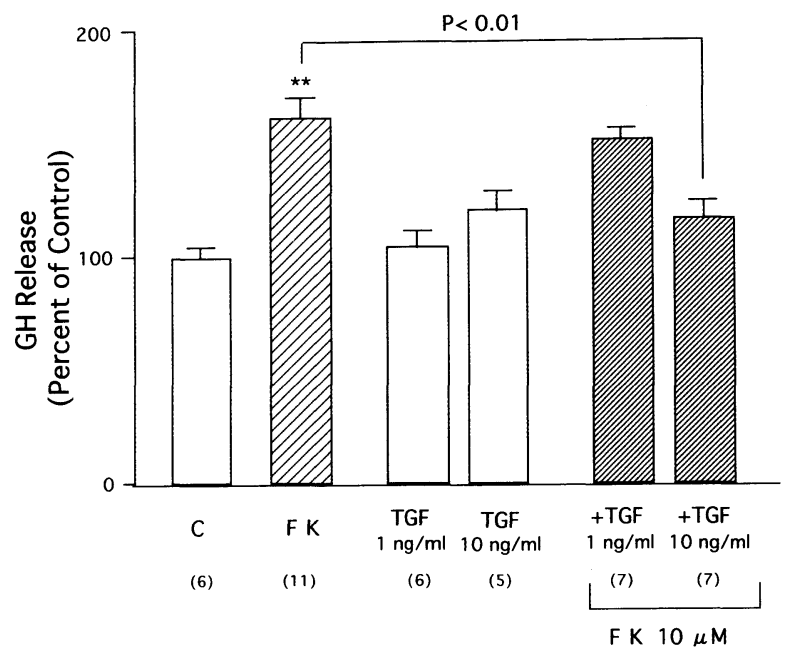

Fig. 4. Effects of TGF on FK-induced GH release from cultured rat anterior pituitary cells. The cells were treated with TGF in the presence of FK for $2 \mathrm{~h}$. Vertical lines represent the SEM. ${ }^{*} P<0.01 v$ s. control (c). Numbers in parentheses indicate the number of observations in each group. 


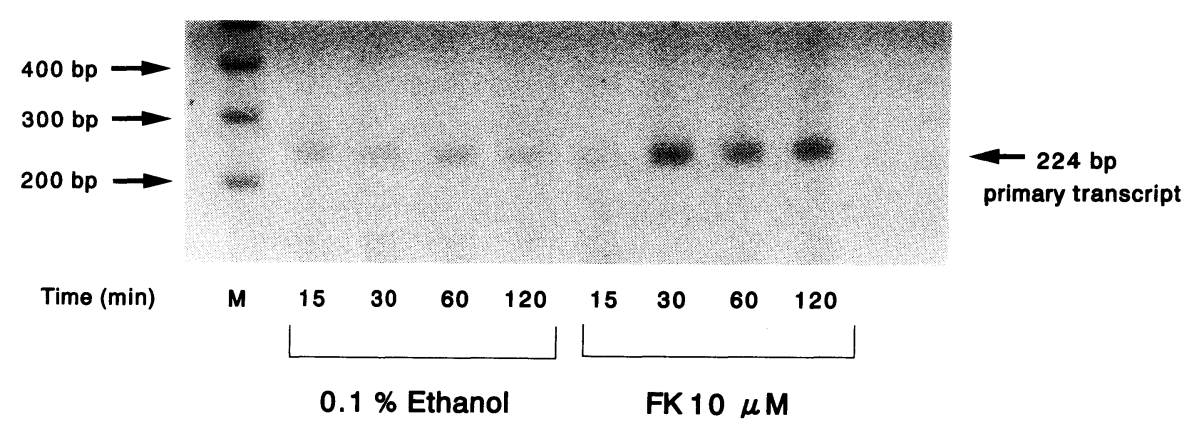

Fig. 5. Effects of FK on the expression of primary transcripts of rat GH gene in cultured rat anterior pituitary cells. The cells were incubated with FK or $0.1 \%$ ethanol for different time periods as indicated in the figure. The primary transcripts (224 bp) of the rat GH gene were detected by intron-specific PCR. FK stimulated the expression of primary transcripts from $30 \mathrm{~min}$ after the incubation. M: molecular marker.

rat GH gene was stimulated by FK in a timedependent manner with the earliest effect occurring at $30 \mathrm{~min}$ (Fig. 5).

\section{Discussion}

The principal immunosuppressant drugs, FK, CyA and RP were introduced to the primary culture system of rat anterior pituitary cells to investigate the intracellular signaling pathway involved in FKinduced GH release in this study. FK significantly increased GH release in a dose-dependent manner as previously reported [6]. Similarly, CyA augmented GH release, although RP had no effect on GH release at the same concentration as FK and CyA. It has already been established that FK and $\mathrm{CyA}$, when bound to their binding proteins such as FKBP12 and cyclophillin, inhibit CaN activity [2]. By contrast, RP does not inhibit CaN activity even though it binds to FKBP12 [2]. Taken together, it is likely that inhibition of CaN activity is primarily responsible for FK-induced GH release from rat somatotropes. Recent reports have indicated that FKBP12 regulates intracellular calcium ion channels [7] but this might play a minor role at least in $\mathrm{GH}$ secretion from somatotropes, since RP did not affect GH secretion. In our study,
Rp significantly inhibited FK-induced GH secretion, suggesting that RP competes with FK through their binding protein, FKBP12, in somatotropes.

Although TGF- $\beta$ itself did not affect basal GH release, it significantly inhibited FK-induced GH release. Recent reports have shown a molecular interaction between FKBP12 and TGF- $\beta$ receptor [11]. Our results also support this interaction on $\mathrm{GH}$ secretion from rat somatotropes. The interaction between FKBP12 and TGF receptors might play an additional role in the FKBP-CaN$\mathrm{GH}$ signalling pathway. In the present study, FK stimulated expression of the primary transcripts of rat GH gene as well as GH release. GH mRNA content does not reflect the transcriptional activity of the GH gene, because a large amount of GH mRNA is stored in somatotropes. The primary transcripts of the GH gene (pre-mRNA) are located in the nuclei of somatotropes and rapidly released into the cytoplasm after splicing, so that the premRNA of the GH gene is also comparable to its transcriptional activity. Our results suggest that the FK-FKBP complex stimulates the transcriptional activity of the rat GH gene. Further studies are required to elucidate whether the complex directly binds to a cis-element of the GH gene or affects trans-elements in somatotropes.

\section{References}

1. Schreiber SL (1992) Immunophilin-sensitive protein phosphatase action in cell signaling pathways. Cell
70: 365-368.

2. Lui J, Farmer JD Jr, Lane WS, Friedman J, Weissman 
I, Schreiber Sl (1991) Calcineurin is a common target of cyclophilin-cyclosporin A and FKBP-FK506 complexes. Cell 66: 807-815.

3. McKeon F (1991) When worlds collide: Immunosuppressants meet protein phosphatases. Cell 66: 823-826.

4. Steiner JP, Dawson TM, Fotuhi M, Glatt CE, Snowman AM, Cohen N, Synder SH (1992) High brain densities of the immunophilin FKBP colocalized with calcineurin. Nature 358: 584-587.

5. Antoni FA, Shipston MJ, Smith SM (1993) Inhibitory role for calcineurin in stimulus-secretion coupling revealed by FK506 and cyclosporin A in pituitary corticotrope tumor cells. Biochem Biophys Res Commun 194: 226-233.

6. Murao K, Sato M, Niimi M, Wada Y, Matsubara S, Takahara J (1996) Immunosuppressant agent FK 506 stimulates growth hormone $(\mathrm{GH})$ secretion and gene expression of hypothalamic GH-releasing hormone in the rat. Endocrinology 137: 1118-1122.
7. Solomon HS, David MS (1995) Immunophilins and the nervous system. Nature Medicine 1: 32-37.

8. Sato M, Takahara J, Fujioka Y, Niimi M, Irino S (1988) Physiological role of growth hormone (GH)releasing factor and somatostatin in the dynamics of GH secretion in adult male rat. Endocrinology 123: 1928-1933.

9. Seeburg PH, Shine J, Martial JA, Baxter JD, Goodman HM (1977) Nucleotide sequence and amplification in bacteria of structural gene for rat growth hormone. Nature 270: 486-494.

10. Sato M, Mizobuchi M, Koji M, Tamaki M, Takahara J (1994) Simple quantitative reverse transcribedpolymerase chain reaction (RT-PCR) method involving recombinant RNA generated by a falsepriming PCR product. J Biochem 116: 1198-1201.

11. Wang T, Donaboe PK, Zervos AS (1994) Specific interaction of type 1 receptors of the TGF- $\beta$ family with the immunophilin FKBP-12. Sience 265: 674676. 